\title{
HIPERTENSÃO ARTERIAL PARA HOMENS: UMA CONDIÇÃO DANOSA E RESTRITIVA
}

\author{
ARTERIAL HYPERTENSION FOR MEN: \\ A DAMAGING AND RESTRICTIVE CONDITION
}

\section{HIPERTENSIÓN ARTERIAL PARA HOMBRES: UNA CONDICIÓN RESTRICTIVA Y DAÑINA}

\author{
Elilian Oliveira Pereira ${ }^{1}$ \\ Fernanda Carneiro Mussi ${ }^{2}$
}

Como citar este artigo: Pereira EO, Mussi FC. Hipertensão arterial para homens: uma condição danosa e restritiva. Rev baiana enferm. 2020;34:e36171.

Objetivo: compreender o significado da hipertensão arterial para homens hipertensos. Método: estudo qualitativo que entrevistou homens hipertensos atendidos em um Centro de Referência para Doenças Cardiovasculares localizado em Salvador, Bahia, Brasil. As entrevistas foram gravadas e transcritas na íntegra. Dos depoimentos foram extraídos os códigos (núcleos de sentido) que foram agrupados por similaridades e diferenças, formando categorias e subcategorias. Resultados: as quatro categorias que evidenciaram o sentido de conviver com a hipertensão foram: Sendo uma condição silenciosa ou um conjunto de sensações corporais desconfortáveis; Sendo um mal que interfere em dimensões da vida; Sendo um mal que rouba ou sequela a vida; e Sendo uma condição que requer privação de excessos e cuidados. Conclusão: os quatro significados atribuídos à hipertensão revelaram o fardo da doença na vida dos homens.

Descritores: Hipertensão. Homens. Compreensão. Conhecimento. Autocuidado.

Objective: to understand the meaning of arterial hypertension for hypertensive men. Method: qualitative study that interviewed bypertensive men treated at a Reference Center for Cardiovascular Diseases located in Salvador, Babia, Brazil. The interviews were recorded and fully transcribed. From the statements, codes (meaning cores) were extracted, which were grouped by similarities and differences, forming categories and subcategories. Results: the four categories that showed the sense of living with bypertension were: Being a silent condition or a set of uncomfortable bodily sensations; Being an illness that interferes in dimensions of life; Being an illness that steals life or brings sequelae; and Being a condition that requires deprivation of excesses and care. Conclusion: the four meanings attributed to bypertension showed the burden of disease in the men's lives.

Descriptors: Hypertension. Men. Comprehension. Knowledge. Self Care.

Objetivo: comprender el significado de la hipertensión arterial para hombres hipertensos. Método: estudio cualitativo que entrevistó a hombres hipertensos tratados en un Centro de Referencia para Enfermedades Cardiovasculares ubicado en Salvador, Babia, Brasil. Las entrevistas fueron grabadas y transcritas en su totalidad. De los testimonios, fueron extraídos los códigos (núcleos de significado) que se agruparon por semejanzas y diferencias, formando las categorias y subcategorias. Resultados: las cuatro categorias que mostraron el sentido de vivir con hipertensión fueron: Ser un estado silencioso o un conjunto de sensaciones corporales incómodas; Ser un mal que interfiere en

\footnotetext{
Enfermeira. Especialista em Enfermagem em Unidade de Terapia Intensiva. Pesquisadora Independente. Salvador, Bahia, Brasil. elilian.pereira@hotmail.com. http:// orcid.org/0000-0002-3720-3202

Enfermeira. Doutora em Enfermagem. Professora Titular da Universidade Federal da Bahia. Salvador, Bahia, Brasil. http://orcid.org/0000-0003-0692-59/2.
} 
las dimensiones de la vida; Ser un mal que roba o secuela a la vida; y Ser una condición que requiere la privación de excesos y cuidado. Conclusión: los cuatro significados que se atribuyen a la bipertensión arterial mostraron la carga de la enfermedad en la vida de los hombres.

Descriptores: Hipertensión. Hombres. Comprensión. Conocimiento. Autocuidado.

\section{Introdução}

A hipertensão arterial é um fator de risco independente e modificável para as doenças cardiovasculares. Possui alta prevalência e baixas taxas de controle, sendo um dos mais importantes problemas de saúde pública, em razão das implicações econômicas e sociais que desafiam a definição de medidas efetivas de prevenção e controle ${ }^{(1-3)}$.

A hipertensão arterial é perpassada por dimensões biológicas, socioeconômicas, emocionais, culturais e ambientais. Assim, o cuidado em saúde/enfermagem pressupõe considerar o que os sujeitos pensam, sentem e conhecem sobre a doença e a perspectiva que têm para o cuidado de $\mathrm{si}^{(4)}$. Por isso, os processos de saúde e doença precisam ser examinados nos contextos históricos, sociais e culturais, com enfoque no sujeito, levando em consideração que a eficácia da terapêutica está estritamente ligada à interpretação do indivíduo sobre a sua condição ${ }^{(5)}$.

Chama-se atenção para a construção sociocultural do processo de adoecimento e para a necessidade de compreensão da pessoa como um ser holístico, ao invés de um corpo portador de uma avaria ${ }^{(6)}$. Nessa perspectiva, o enfoque do cuidado é o sujeito que está convivendo com uma condição de saúde que o acompanha e cuja forma de lidar, compreender e explicá-la decorre de um movimento em que a atribuição de significado e a ação realizam-se reciprocamente, balizadas pelo contexto sociocultural ${ }^{(7)}$.

A hipertensão arterial apresenta características peculiares, que influenciam na percepção da pessoa sobre a doença e repercutem na dinâmica de vida e nas relações sociais. Sendo uma doença crônica, demanda tratamento e acompanhamento contínuo, podendo gerar agravos e dependência de uso de medicamentos. Requer também mudanças nos hábitos de vida, que incluem restrições alimentares, prática de atividade física, abandono do tabagismo, moderação no consumo de bebida alcoólica, minimização do estresse, entre outras ${ }^{(8)}$.

A compreensão da doença e as ações para o controle também podem variar em razão das construções sociais de masculinidade. O estereótipo masculino é de um sujeito forte, produtivo, viril e invulnerável, do qual não se espera sensibilidade, fragilidade, dependência e cuidado ${ }^{(9)}$. Os homens, em geral, caracterizam-se por não priorizar os cuidados com a própria saúde e pela baixa procura de serviços de atenção primária, comprometendo a proteção necessária à preservação da saúde. Em geral, adentram ao sistema de saúde pela atenção especializada, o que tem como consequência maior morbidade e mortalidade ${ }^{(10-11)}$. Além disso, o modo como vivenciam e compreendem a doença pode influenciar nas ações de autocuidado e (re)orientar as práticas de cuidar em saúde.

Todavia, ainda hoje, pouco se sabe sobre como a hipertensão arterial é compreendida pelos homens. Em revisão de literatura na Biblioteca Virtual de Saúde, em todas as fontes disponíveis, sem delimitação de período, empregando-se, em espanhol, português e inglês, os unitermos hipertensão and homens and compreensão, hipertensão and homens and crença, hipertensão and homens and conhecimento, constatou-se que existem estudos sobre a hipertensão arterial na perspectiva dos sujeitos, mas poucos foram realizados com homens e não foram identificadas investigações sobre a compreensão da doença na perspectiva deles.

Com base no exposto, constituiu-se em objetivo deste estudo compreender o significado da hipertensão arterial para homens hipertensos. 


\section{Método}

A pesquisa qualitativa integra um projeto matriz e foi realizada em um Centro de Referência para Doenças Cardiovasculares, no município de Salvador, Bahia, Brasil, no qual funcionava um núcleo de atendimento para o Programa de Saúde do Homem do Ministério da Saúde ${ }^{(12)}$. A instituição oferecia atendimento multiprofissional, serviços de apoio e diagnóstico e atendia a uma demanda significativa de usuários do Sistema Único de Saúde (SUS) com hipertensão arterial, no âmbito da atenção primária a saúde. Os homens eram submetidos a uma triagem inicial para avaliação das necessidades de saúde e, posteriormente, encaminhados para atendimentos especializados.

Os 80 participantes foram homens que atenderam aos seguintes critérios de inclusão do projeto matriz: ser acompanhado no Programa de Saúde do Homem; ter diagnóstico médico de hipertensão arterial; ter idade igual ou superior a 20 anos; estar consciente, orientado no tempo e espaço; e ter celular para recebimento de torpedos de mensagens.

Utilizou-se neste estudo duas partes do instrumento de pesquisa do projeto matriz. A Parte I, denominada "Dados de caracterização sociodemográfica”, que incluiu questões fechadas sobre idade, raça/cor autodeclarada, estado civil, escolaridade, situação laboral, renda familiar mensal, número de filhos e dependentes. A Parte II constou de perguntas semiestruturadas para a compreensão do significado da hipertensão arterial, a exemplo de: Como é viver com pressão alta? O que você entende por pressão alta? O que você acha que causou a pressão alta? O que você acredita que pode ajudar a controlar a pressão alta? No decorrer da entrevista, outras perguntas foram feitas com o intuito de elucidar pontos que não ficaram claros ou para ajudar a recompor o contexto da questão.

Após a confirmação do diagnóstico médico de hipertensão arterial no prontuário e identificação dos demais critérios de inclusão, os homens foram abordados na sala de espera do local de estudo, antes ou após a consulta médica. Nesse momento, explicava-se a finalidade do estudo e questionava-se sobre aceitarem participar. Após aquiescência, eram recebidos em sala privativa, sendo explicado o Termo de Consentimento Livre e Esclarecido, o qual foi assinado em duas vias. Os instrumentos foram aplicados mediante entrevista, pelas pesquisadoras devidamente treinadas. As entrevistas foram gravadas e, posteriormente, transcritas na íntegra. A coleta de dados ocorreu no período de outubro de 2013 a abril de 2014.

As variáveis sociodemográficas foram analisadas em frequências absolutas e percentuais, médias e desvio padrão. As respostas das questões semiestruturadas foram lidas exaustivamente e examinadas minuciosamente, linha por linha, para extrair os primeiros códigos (núcleos de sentido). Pelo processo de comparação, os códigos identificados foram agrupados por similaridades e diferenças, formando as categorias e subcategorias que expressaram o significado da hipertensão ${ }^{(13)}$, as quais foram descritas e ilustradas com depoimentos dos participantes e apresentadas em quadros, com os respectivos códigos.

O projeto matriz foi aprovado pelo Parecer n. 268.722, do Comitê de Ética da Escola de Enfermagem da Universidade Federal da Bahia (UFBA), em 3/4/2013. A pesquisa atendeu à Resolução n. 466, de 12 de dezembro de 2012, do Conselho Nacional de Saúde.

\section{Resultados}

No tocante às características sociodemográficas, a idade mínima dos homens foi de 36 e a máxima de 80 anos, média de idade de 58,46 anos (DP=8,64). Predominaram casados/união estável $(70,0 \%)$ e autodeclarados da raça/cor negra (91,2\%). Maior proporção cursou até o 1o grau $(47,5 \%)$, seguidos daqueles que cursaram até o $2^{\circ}$ grau $(46,2 \%)$. A maioria exercia atividade profissional sendo autônomo/empregado ou aposentado com atividade (63,7\%). Alguns (36,3\%) eram inativos em razão de aposentadoria ou desemprego. Maior proporção tinha renda familiar mensal de até dois salários mínimos (57,5\%), seguida da renda maior ou igual a três 
salários (42,5\%). Do total de entrevistados, 95,0\% eram os responsáveis pela família e 98,8\% eram procedentes de Salvador e Região Metropolitana.

Quanto ao significado da hipertensão arterial na perspectiva de homens hipertensos, quatro categorias expressaram esse significado: Sendo uma condição silenciosa ou um conjunto de sensações corporais desconfortáveis; Sendo um mal que interfere em dimensões da vida; Sendo um mal que rouba ou sequela a vida; Sendo uma condição que requer cuidados e privação de excessos.

\section{Sendo uma condição silenciosa ou um conjunto de sensações corporais desconfortáveis}

Para alguns homens, essa condição significou que a doença torna-se aparente pelos sintomas. Para outros, é uma marca silenciosa e traiçoeira no corpo, pois não emite sinais. Em ambas as situações, a doença é um mal que os acomete. Essa categoria está representada por duas subcategorias: Sendo um desconforto físico e Sendo uma condição imperceptível. Os códigos que as ilustram constam no Quadro 1.

Quadro 1 - Categoria "Sendo uma condição silenciosa ou um conjunto de sensações corporais desconfortáveis", subcategorias e exemplos de códigos

\begin{tabular}{|c|c|c|}
\hline Categoria & Subcategorias & Exemplos de códigos \\
\hline \multirow[t]{2}{*}{$\begin{array}{l}\text { Sendo uma } \\
\text { condição } \\
\text { silenciosa ou } \\
\text { um conjunto } \\
\text { de sensações } \\
\text { corporais } \\
\text { desconfortáveis }\end{array}$} & $\begin{array}{l}\text { Sendo um } \\
\text { desconforto } \\
\text { físico }\end{array}$ & $\begin{array}{l}\text { Deixando com mal-estar; } \\
\text { Sentindo um mal-estar; } \\
\text { Deixando com tremor; } \\
\text { Sentindo palpitação; } \\
\text { Sentindo o coração bater mais forte; } \\
\text { Deixando com dor de cabeça; } \\
\text { Sentindo uma pontada na cabeça; } \\
\text { Sentindo dor de cabeça... tá alta; } \\
\text { Dando dor na nuca/cabeça; } \\
\text { Sentindo o pescoço bombeando; } \\
\text { Ficando tonto; } \\
\text { Sentindo falta de ar; } \\
\text { Sentindo a perna endurecer; } \\
\text { Sentindo a vista escurecer. }\end{array}$ \\
\hline & $\begin{array}{l}\text { Sendo uma } \\
\text { condição } \\
\text { imperceptível }\end{array}$ & $\begin{array}{l}\text { Tendo uma doença silenciosa; } \\
\text { Não sentindo nada quando está alta; } \\
\text { Ficando surpreso com a pressão alta; } \\
\text { Sendo algo que aumenta por ela mesma; } \\
\text { Aumentando de uma hora para a outra; } \\
\text { Começando de uma hora para a outra; } \\
\text { Sendo algo que só identifica quando "tira" a pressão; } \\
\text { Não tendo nenhum sintoma para prever que está alta e tomar remédio; } \\
\text { Nunca sentindo nada e quando viu a pressão estava alta. }\end{array}$ \\
\hline
\end{tabular}

Fonte: Elaboração própria.

A subcategoria "Sendo um desconforto físico" expressa que os homens compreendem a hipertensão arterial pela presença de sintomas físicos caracterizados como mal-estar, tremor, dor na nuca, tontura, falta de ar, vista escura, pernas endurecidas, coração batendo diferente.

A pressão alta é como se tivesse uma dor na cabeça, uma
dor na nuca. (E 50$)$.

É quando eu estou ficando tonto. Se ficar tonto, já sei que a pressão tá alta. (E 59).
A hipertensão é também compreendida por alguns homens como "Sendo uma condição imperceptível", isto é, não há indícios ou sinais da sua existência.

Quando a minha pressão tá alta, eu não sinto diferença nenbuma. (E 51).

Quando a pressão está alta, não se sente um sintoma de imediato para prever que está alta, a não ser quando vai ao médico e mede. (E 78). 
Sendo um mal que interfere em dimensões da vida

Com ou sem a manifestação de sintomas, os homens compreendem que a vida está afetada pela presença da doença, como expressou a categoria, ao revelar que a hipertensão significa prejuízo para o descanso e o lazer, além de abalar a sexualidade. Está representada por três subcategorias, conforme ilustra o Quadro 2.

Quadro 2 - Categoria "Sendo um mal que interfere em dimensões da vida", subcategorias e exemplos de códigos

\begin{tabular}{|c|c|c|}
\hline Categoria & Subcategorias & Exemplos de códigos \\
\hline \multirow{3}{*}{$\begin{array}{l}\text { Sendo um mal } \\
\text { que interfere em } \\
\text { dimensões da vida }\end{array}$} & $\begin{array}{l}\text { Prejudicando o } \\
\text { descanso }\end{array}$ & $\begin{array}{l}\text { Não conseguindo dormir, se a pressão está alta; } \\
\text { Não conseguindo descansar, quando a pressão está alta. }\end{array}$ \\
\hline & Atingindo o lazer & $\begin{array}{l}\text { Deixando de ir para a festa, por medo de passar mal e } \\
\text { atrapalhar os amigos; } \\
\text { Deixando de ir à seresta, por medo de passar mal; } \\
\text { Parando de jogar bola no fim de semana, porque é prejudicial. }\end{array}$ \\
\hline & $\begin{array}{l}\text { Abalando a } \\
\text { sexualidade }\end{array}$ & $\begin{array}{l}\text { Ficando com a sexualidade abalada; } \\
\text { Sentindo impotência por causa do medicamento. }\end{array}$ \\
\hline
\end{tabular}

Fonte: Elaboração própria.

A subcategoria "Prejudicando o descanso" revelou que ser hipertenso significa ter o sono e o repouso afetados quando a pressão está alta, sofrer de insônia e ter dificuldade para relaxar.

\footnotetext{
A pressão alta causa um dano da seguinte forma; se eu tiver com a pressão alta, eu não consigo dormir. Fica aquela insônia. (E 2).
}

"Atingindo o lazer" foi a subcategoria que mostrou que ser hipertenso significa abandonar atividades de diversão, por medo de passar mal ou considerá-las prejudiciais.

Deixei de ir pra festa, tudo por causa do problema dessa doença. Antes eu ia para a seresta, para tudo que é lugar. Ia pescar e já não vou mais, com medo de passar mal e empatar os colegas. (E 65).

"Abalando a sexualidade" foi a subcategoria que revelou que os homens podem se perceber impotentes, mais cansados e ofegantes no exercício da sexualidade.
O que mais está me incomodando e deixando com dilemas emocionais é em relação a sexualidade. Se eu tomar o remédio, atinge direto minha sexualidade. Agora eu estou me sentindo impotente. (E 54).

Além da hipertensão ser significada como um mal que afeta negativamente várias dimensões da vida que dão sentido à existência dos homens, também é compreendida como uma condição grave, perigosa e persistente, pois traz complicações e sequelas, sacrifica órgãos vitais, podendo deixar a pessoa dependente de cuidados e com alterações funcionais permanentes. Entretanto, não marca apenas a vida com sequelas. A extensão de seu dano é maior; é a perda da própria vida. É uma doença assassina. Assim, ter hipertensão significa viver um medo permanente, é a antecipação de um mal, conforme expressa a categoria "Sendo um mal que rouba ou sequela a vida", no Quadro 3.

Quadro 3 - Categoria "Sendo um mal que rouba ou sequela a vida", subcategorias e exemplos de códigos

(continua)

\begin{tabular}{|l|l|l|}
\hline \multicolumn{1}{|c|}{ Categoria } & Subcategorias & \multicolumn{1}{c|}{ Exemplos de códigos } \\
\hline $\begin{array}{l}\text { Sendo um mal } \\
\text { que rouba ou } \\
\text { sequela a vida }\end{array}$ & Podendo levar à & Sendo uma doença muito perigosa; \\
& & Causando perigo; \\
& & Sendo perigosa quando altíssima; \\
& & Sendo um problema seríssimo; \\
& Entendendo como uma doença grave; \\
& Sendo algo que mata, como dizem os médicos; \\
& Podendo matar, se não cuidar; \\
\hline
\end{tabular}


Quadro 3 - Categoria "Sendo um mal que rouba ou sequela a vida", subcategorias e exemplos de códigos

\begin{tabular}{|c|c|c|}
\hline Categoria & Subcategorias & Exemplos de códigos \\
\hline \multirow[t]{2}{*}{$\begin{array}{l}\text { Sendo um mal } \\
\text { que rouba ou } \\
\text { sequela a vida }\end{array}$} & $\begin{array}{l}\text { Podendo levar à } \\
\text { morte }\end{array}$ & $\begin{array}{l}\text { Sendo algo que mata; } \\
\text { Tendo risco de vida; } \\
\text { Podendo ter uma morte súbita; } \\
\text { Podendo ter um mal súbito a qualquer momento; } \\
\text { Sendo uma assassina silenciosa. }\end{array}$ \\
\hline & $\begin{array}{l}\text { Podendo ficar } \\
\text { incapaz }\end{array}$ & $\begin{array}{l}\text { Sendo uma doença irreversível; } \\
\text { Ficando preocupado e ansioso quando descobriu a doença; } \\
\text { Só tendo noção do perigo da pressão alta, quando teve } \\
\text { acidente vascular cerebral (AVC); } \\
\text { Podendo levar a pessoa para cama por causa do AVC; } \\
\text { Podendo ter derrame; } \\
\text { Podendo ter o mesmo fim (derrame) que a mãe e o pai; } \\
\text { Deixando dependente de cuidado; } \\
\text { Podendo ficar em cima de uma cama; } \\
\text { Podendo ter que usar fralda, se tiver derrame; } \\
\text { Causando sequelas irreversíveis; } \\
\text { Podendo ter um infarto; } \\
\text { Trazendo risco para o coração; } \\
\text { Podendo sacrificar o rim; } \\
\text { Sendo uma coisa má, que ataca a coronária e o rim; } \\
\text { Podendo chegar a ponto de fazer hemodiálise; } \\
\text { Correndo risco de infarto, parada; } \\
\text { Podendo se prejudicar; } \\
\text { Podendo ter problema no futuro. }\end{array}$ \\
\hline
\end{tabular}

Fonte: Elaboração própria.

A subcategoria "Podendo levar à morte" revelou que a hipertensão significa perigo, causa medo pelo risco que impõe à vida; é viver sob ameaça de morte.

No meu conbecimento, a pressão alta chama-se de risco de vida. (E 6).

Eu entendo como uma doença perigosa e que pode matar. (E 9).

Você está sujeito a ter um mal súbito a qualquer momento, mesmo fazendo uso da medicação. (E 38).

A pressão é um negócio que mata. (E 2).

A subcategoria "Podendo ficar incapaz" evidenciou que a hipertensão também significa apreensão, temor, preocupação por algo presente no corpo que afeta órgãos, sequela o corpo e pode gerar dependência de cuidados.

A pressão é algo doloroso. Muitas vezes a gente sofre derrame, devido à pressão, fica usando fralda. É uma coisa bastante dolorosa que a pressão causa. (E 2).

Dá um derrame, que nem meu pai e minha mãe, que eu estava vendo a hora de ter esse mesmo fim. (E 16).
É uma doença que pode causar sequelas irreversíveis. (E 9).

Se não cuidar, ela pode levar até a um infarto, derrame. (E 24).

\section{Sendo uma condição que requer privação de excessos e cuidados}

Esta categoria revelou que ter a doença significa estado de alerta, de precaução. Implica em tomar cuidados, remédios, aderir a condutas médicas, buscar ajuda para incorporá-las à vida cotidiana e até mesmo encontrar tratamentos alternativos. Incorporando certos cuidados, veem a chance de adiar a morte e prevenir as incapacidades. É o medo da morte e a vontade de viver que mobiliza o cuidado de si, mesmo que implique em restrições a prazeres e vontades. Sendo uma condição que requer cuidados, para evitar a morte e as sequelas, significou também os desafios e as privações vividos na tentativa de controlar a doença, como ilustram as subcategorias no Quadro 4. 
Quadro 4-Categoria "Sendo uma condição que requer privação de excessos e cuidados", subcategorias e exemplos de códigos

\begin{tabular}{|c|c|c|}
\hline Categoria & Subcategorias & Exemplos de códigos \\
\hline \multirow[t]{5}{*}{$\begin{array}{l}\text { Sendo uma } \\
\text { condição } \\
\text { que requer } \\
\text { privação de } \\
\text { excessos e } \\
\text { cuidados }\end{array}$} & $\begin{array}{l}\text { Limitando comer e } \\
\text { beber o que gosta }\end{array}$ & $\begin{array}{l}\text { Tendo que evitar sal; } \\
\text { Controlando o sal; } \\
\text { Cortando sal; } \\
\text { Não comendo o sal; } \\
\text { Sendo proibido de comer sal; } \\
\text { Parando de comer sal puro, porque o médico proibiu; } \\
\text { Controlando a alimentação; } \\
\text { Regulando a alimentação; } \\
\text { Tendo que comer pouco; } \\
\text { Parando de comer comida pesada a noite; } \\
\text { Parando de jantar de noite; } \\
\text { Fazendo dieta; } \\
\text { Tendo que mudar a alimentação; } \\
\text { Tendo refeições sadias; } \\
\text { Tendo que comer em quantidade menor; } \\
\text { Evitando gordura; } \\
\text { Tendo que evitar fritura; } \\
\text { Parando de comer toucinho, porque o médico proibiu; } \\
\text { Tendo que parar de comer carne de porco; } \\
\text { Parando de comer com caldo de gordura; } \\
\text { Cortando carne de sertão; } \\
\text { Evitando feijoada; } \\
\text { Evitando mocotó; } \\
\text { Tendo que parar de comer massa; } \\
\text { Tendo que evitar refrigerante; } \\
\text { Parando de beber; } \\
\text { Tendo que parar de beber; } \\
\text { Deixando de ingerir muita bebida alcoólica. }\end{array}$ \\
\hline & Largando o fumo & $\begin{array}{l}\text { Tendo que parar de fumar; } \\
\text { Tendo que se livrar do cigarro; } \\
\text { Precisando de ajuda para parar de fumar. }\end{array}$ \\
\hline & $\begin{array}{l}\text { Tendo que tomar } \\
\text { remédios }\end{array}$ & $\begin{array}{l}\text { Tendo que tomar os remédios; } \\
\text { Tomando os remédios diariamente; } \\
\text { Tendo que tomar o remédio na hora certa; } \\
\text { Não podendo parar a medicação, que ela vai lá para cima; } \\
\text { Tendo uma doença que deixa todo mundo à base de } \\
\text { medicação; } \\
\text { Sendo ruim tomar os remédios todos os dias; } \\
\text { Querendo parar de tomar o medicamento; } \\
\text { Sem saber por que não pode deixar de tomar a medicação, já } \\
\text { que a pressão está controlada. }\end{array}$ \\
\hline & $\begin{array}{l}\text { Recorrendo } \\
\text { a tratamentos } \\
\text { alternativos }\end{array}$ & $\begin{array}{l}\text { Tomando um chazinho; } \\
\text { Fazendo o que o pessoal ensina para abaixar a pressão; } \\
\text { Tomando remédios caseiros; } \\
\text { Tomando o chá que as pessoas ensinam. }\end{array}$ \\
\hline & $\begin{array}{l}\text { Tendo que fazer } \\
\text { atividade física }\end{array}$ & $\begin{array}{l}\text { Tendo que andar diariamente; } \\
\text { Tendo que fazer uma caminhada; } \\
\text { Precisando achar tempo para caminhar. }\end{array}$ \\
\hline
\end{tabular}


Quadro 4-Categoria "Sendo uma condição que requer privação de excessos e cuidados", subcategorias e exemplos de códigos

\begin{tabular}{|l|l|l|}
\hline Categoria & Subcategorias & Exemplos de códigos \\
\hline Sendo uma & Tentando não se & Não podendo se aborrecer; \\
condição & aborrecer & Tendo que se controlar ao máximo, para não se aborrecer; \\
que requer & & Não levando tudo a ponto de faca; \\
privação de & & Tendo calma com as coisas que faz; \\
excessos e & & Procurando não se estressar; \\
cuidados & & Tendo que controlar o estresse; \\
& & Não esquentando mais com nada; \\
& & Evitando se zangar; \\
& & Tendo que se acalmar para baixar a pressão; \\
& Controlando com um bom humor; \\
& Diminuindo a pressão do trabalho; \\
& Buscando ajuda de um psicólogo. \\
\hline
\end{tabular}

Fonte: Elaboração própria.

A subcategoria "Limitando comer e beber o que gosta" significou que a hipertensão demanda abdicar de excessos, limitar o consumo da bebida alcoólica, de sal, de comidas gordurosas, massas, entre outros, os quais eram apreciados antes.

Sei que tem que mudar a alimentação, não pode comer
fritura. (E 22).

Eu tive que diminuir um bocado de coisa, comer pouco, comer menos, não comer fritura, gordura, tenho que comer um negócio grelhado, tô parando de jantar a noite. (E 48).

O controle que eu tô fazendo é evitando o sal. O sal é um perigo! (E 59).

O controle é deixar a bebida. Não bebo mais e vem diminuindo a pressão. (E 29).

É não comer sal, não tomar café. O médico proibiu essas coisas. (E 26).

A subcategoria "Largando o fumo" significou ter que abandonar o cigarro e a necessidade de ajuda para parar de fumar.

A ajuda que eu preciso pra controlar é deixar de fumar. (E 24).

O controle é parar de fumar. (E 49).

Eu me livrei do cigarro, porque era o maior mal que eu tinha. (E 35).

"Tendo que tomar os remédios" foi a subcategoria que significou a necessidade de incorporar medicamentos aos hábitos de vida. É ter que estar atento ao remédio e a hora certa de tomar, para evitar a elevação da pressão. Incorporar os remédios é ruim. Por vezes pensam ou manifestam o desejo de ficar livres das drogas, questionam a sua necessidade quando a pressão não está alta e alimentam a perspectiva de cura.

\footnotetext{
Tô tomando o remédio porque já ajudou bastante. Tá mais controlada. (E 3).

Apesar de ter todo o controle, será que haverá cura? (E 44).

Eu queria saber se dá pra ficar livre da medicação. Ela tá controlada já. (E 55).

Eu não posso deixar de tomar o medicamento. Por mim já tinha parado, mas aí ela vai lá pra cima. (E 49).
}

"Recorrendo a tratamentos alternativos" foi a subcategoria que evidenciou a busca de alternativas populares para controlar a pressão. Tomam remédios caseiros e certos tipos de chá, seguem ensinamentos populares na tentativa de baixar a pressão. Eu comecei a tomar um chá para abaixar a pressão.
Eu procuro fazer o que o pessoal diz que termina baixan-
do a pressão. (E 35 ).

Eu tomo os remédios que o médico passa e um medicamento caseiro, que me faz muito bem. (E 58).

A subcategoria "Tendo que fazer atividade física" significou ter que realizar atividade física, fazer exercício, movimentar-se e, assim, abrir um espaço no dia a dia para essa finalidade.

É andar diariamente, que foi o conselbo que o médico deu, numa média de 50 minutos por dia. (E 1).

É fazer o exercício que não fazia. Agora tô dando umas caminhadinhas. (E 22).

"Tentando não se aborrecer" foi a subcategoria que expressou a tentativa dos homens de evitar aborrecimentos, preocupações, evitar 
zangar-se e levar tudo a "ponto de faca", ter mais calma e bom humor e até mesmo buscar a ajuda de um psicólogo.

Se eu me aborrecer, a pressão sobe. (E 4).

É eu não me preocupar com o que tá acontecendo. (E 5).

É aprender a controlar, a não levar tudo a ponto de faca, o que tá me ajudando é o psicólogo. (E 28).

O que vai controlar é ter um bom humor. (E 61).

É eu diminuir a pressão no sistema, no trabalbo. Isso ajuda muito. (E 74).

Os quatro significados atribuídos à hipertensão, expressos nas categorias, evidenciaram o impacto e as marcas da doença no corpo e na alma dos homens.

\section{Discussão}

Os homens estudados eram majoritariamente adultos maduros, fase em que há aumento da prevalência da hipertensão arterial ${ }^{(14-15)}$. Autodeclararam-se, em maioria, da raça/cor negra, a qual é um fator de risco para a doença ${ }^{(16)}$. O estudo foi também desenvolvido em município em que predomina a presença do traço de miscigenação ${ }^{(17)}$. A baixa escolaridade é inversamente proporcional à ocorrência de hipertensão ${ }^{(15-16)}$. Os homens caracterizaram-se predominantemente pela renda mensal e nível de escolaridade baixos, portanto em condição de desigualdade social. Sem dúvida, esse perfil sociodemográfico aponta para a necessidade de a equipe de saúde considerar as condições sociais e culturais nas estratégias de prevenção e controle da hipertensão arterial. Revela também a importância de políticas públicas efetivas voltadas ao controle da doença.

Os quatro significados atribuídos à hipertensão arterial, expressos pelas categorias e subcategorias deste estudo, revelaram que a doença anuncia-se por sintomas ou ocorria de modo silencioso, afetava negativamente várias dimensões da vida, tornava o medo um objeto de interação constante em razão da percepção da gravidade do mal que os acometia e que podia roubar-lhes a vida. Assim, o controle demandava abdicar de prazeres, banir excessos, tomar remédios, incorporar novos hábitos, controlar tensões e emoções. Os resultados evidenciaram que a hipertensão arterial era significada como perigosa e restritiva.

A categoria Sendo uma condição silenciosa ou um conjunto de sensações corporais desconfortáveis revelou que a hipertensão arterial era um mal que se manifestava por sintomas ou desconfortos físicos que afetavam o corpo como já constatado em outros estudos ${ }^{(18-19)}$. O sintoma é uma das informações presentes no processo de construção da percepção da doença ${ }^{(20)}$. É um sinal de que algo não vai bem e mobiliza para o cuidado ${ }^{(21)}$. Contudo, os resultados deste estudo também mostraram que, para homens sem sintomas, o rompimento do silêncio da doença ocorreu na interação com os níveis da pressão arterial elevados no momento da sua aferição. É nessa situação que alguma dimensão da corporalidade fica comprometida e a doença é confirmada ou reafirmada ${ }^{(8)}$. A característica assintomática da hipertensão arterial faz com que seja marcada pela casualidade da descoberta, podendo gerar indignação e desconfiança ${ }^{(8)}$, especialmente porque a construção social da masculinidade remete à ideia de que o homem é um sujeito forte, viril, invulnerável e provedor. Portanto, demandar cuidados de saúde é algo que os desmerece, já que são sujeitos criados para assistir e prover, o que acarreta maior dificuldade para se autoperceberem doentes e antecipar a prevenção da doença ${ }^{(9)}$.

Embora a ausência de sintomas não sinalize a elevação da pressão e possa comprometer a lembrança para o uso de medicamentos, não elimina a percepção da gravidade da doença, uma vez diagnosticada, como mostrou a categoria Sendo um mal que rouba ou sequela a vida.

A categoria Sendo um mal que interfere em dimensões da vida reforça que a hipertensão não é invisível para os homens, pois causa alterações expressivas no modo de viver e na percepção sobre si, afetando várias dimensões da vida ${ }^{(22)}$. Nesse estudo, a hipertensão trouxe desconforto físico, interferiu no lazer, no descanso e na sexualidade. Assim, ter a vida afetada pela doença muda a imagem que a pessoa tem de si e traz 
sofrimento e preocupação, além de interferir no convívio social e comprometer a qualidade de vida. Para os homens, assumir os impactos e medos advindos da vivência com a hipertensão pode fragilizar a concepção de masculinidade, pois o sofrimento dela decorrente torna-se evidente. Outros estudos corroboram esses resultados, ao mostrarem que a doença afeta a esfera psicológica, familiar e econômica de pessoas hipertensas ${ }^{(8,23)}$. Esses achados reiteram que é preciso considerar, no processo de cuidado, a experiência de vida e a subjetividade no processo de adoecer e cuidar de $\mathrm{si}^{(6)}$.

A vida dos homens hipertensos estava fortemente marcada pelo medo, conforme expressou a categoria Sendo um mal que rouba ou sequela a vida. Ter hipertensão arterial era visto como temer a perda permanente da vida; temer um rasgo na vida, pela possibilidade de incapacidades e da perda da independência para o cuidado de si; romper com a imagem de ser invulnerável e forte. Em outros estudos, a percepção de que a doença pode causar a morte foi comum nas falas dos usuários ${ }^{(18-19,23)}$. Assim, a doença constitui-se em um dano à totalidade da existência, pois não é apenas o sintoma ou a elevação da pressão arterial que incomoda, mas é a totalidade da pessoa que sofre ${ }^{(8)}$.

O medo dos danos provocados pela doença levou os homens a ter cautela e a regular comportamentos na tentativa de preservar a vida, como mostrou a categoria Sendo uma condição que requer cuidados para evitar a morte e sequelas. A hipertensão arterial tem características peculiares, pois se trata de uma doença que pode ser controlada, mas não curada. Requer tratamento por toda a vida, exige mudanças nem sempre desejadas no estilo de vida, persistência para a continuidade do tratamento e necessidade de cuidados constantes. As mudanças requeridas para o controle da hipertensão arterial afetam o cotidiano e as várias dimensões da vida dos homens e vai contra o padrão de masculinidade imposto socialmente, no qual o homem não adoece, não deixa de fazer coisas ${ }^{(9)}$.

As condições crônicas representam problemas de saúde que exigem gerenciamento contínuo ${ }^{(23)}$.
Na tentativa de controlar a doença ou na ilusão de cura, os homens tentam adequar-se às recomendações médicas, mas aderir à mudança tem um custo: a renúncia do que oferece prazer. É preciso combater os excessos na bebida, na alimentação, no fumo e a inatividade física. Além disso, é preciso a medicalização da vida e dar conta de controlar emoções, mesmo diante de adversidades e do estresse da vida de todo dia. É com dificuldade que os homens enfrentam a necessidade de mudanças construídas e reforçadas socialmente ${ }^{(6)}$.

As categorias que expressaram os significados atribuídos à hipertensão arterial mostraram a vida com a doença: uma vida com medo, preocupação, medicamentos, controles e mudanças. Esses resultados podem desencadear a reflexão da equipe de saúde sobre como pode ajudar os homens hipertensos a enfrentar a cronicidade da doença sem considerá-la um fardo. A(o) enfermeira(o) pode tentar motivar e ajudar as pessoas a encontrarem, no âmbito de suas possibilidades, novas formas de ser e melhor viver, que extrapolem o sentido da restrição para o de preservação de projetos de vida. Reside aí um desafio a ser alcançado por esses trabalhadores de modo articulado com o trabalho dos demais profissionais de saúde.

É preciso lembrar que o sentido da intervenção técnica não deve ser apenas o estado de saúde visado de antemão, nem somente a aplicação mecânica das tecnologias disponíveis para alcançar esse estado. Requer também o exame da relação entre finalidades e meios e seu sentido prático, pois cuidar da saúde de alguém é mais que intervir sobre um objeto; há que se estabelecer uma relação, para se conhecer o projeto de felicidade daquele sujeito ${ }^{(24)}$.

Apesar das construções sociais da masculinidade, que levam muitos homens a alimentar a crença de que são invulneráveis ao adoecimento e a entender o adoecimento como sinal de fragilidade, os resultados deste estudo exprimem que os homens reconheceram as marcas negativas da hipertensão em várias dimensões de sua vida e sentiram-se ameaçados pela doença que os acometia. Nesse contexto, a(o) enfermeira(o) 
pode tentar minimizar o medo provocado pela doença, com abordagens de acolhimento que ajudem os homens a expressar suas fragilidades e vulnerabilidades e a encontrar caminhos para o seu enfrentamento.

É preciso apoiá-los nas mudanças de hábitos necessárias ao controle da hipertensão, sem que a mudança seja estimulada pela ameaça do que pode acontecer, mas sim como uma forma de poderem abrir mão de alguns prazeres, para desfrutar dos projetos de vida fundamentais na vida, no cuidado de si motivado pela preservação de prazeres superiores. Uma vez hipertensos precisarão conviver com cuidados e tratamentos de longa duração, que certamente podem ser adequados e incorporados sem que consistam em ameaças a encontros sociais e ao exercício da sexualidade.

É necessário também fortalecer e qualificar a atenção primária à saúde, garantindo a promoção da saúde e o acolhimento e reconhecimento das necessidades e dos direitos dos homens nos serviços de saúde. Conhecer os riscos da falta de controle da pressão arterial é necessário, mas esse não pode ser interiorizado de forma a viverem em alerta constante.

Como limitação do estudo destaca-se a realização com uma população local, podendo representar percepções de um grupo particular.

\section{Conclusão}

Os significados atribuídos à hipertensão arterial pelos homens hipertensos foram expressos pelas categorias: Sendo uma condição silenciosa ou um conjunto de sensações corporais desconfortáveis; Sendo um mal que interfere em dimensões da vida; Sendo um mal que rouba ou sequela a vida; e Sendo uma condição que requer privação de excessos e cuidados.

Essas categorias evidenciaram a hipertensão como uma condição danosa e restritiva. Revelaram a complexidade de conviver com uma doença crônica, seja pelas abdicações e cuidados contínuos exigidos, seja pelo medo de sequelas e da morte. A doença é significada como um mal que afeta a vida em diversas dimensões.
Os resultados evidenciam a necessidade de se ampliar a abordagem de homens com hipertensão para além dos problemas relacionados à esfera físico-biológica.

O cuidado em saúde/enfermagem pode minimizar o sofrimento e potencializar o cuidado de si como forma de preservação de projetos de vida que promovam sentido à existência. O cuidado integral e multidisciplinar junto a homens hipertensos, levando em consideração as questões de gênero, as suas particularidades e o sentido atribuído à doença, assim como o acolhimento e o estabelecimento de uma relação dialógica entre quem cuida e aquele que é cuidado, poderá facilitar o seguimento do tratamento, reduzir os níveis pressóricos, os fatores de risco associados e as complicações advindas da HAS. Poderá também contribuir para minimizar o fardo da hipertensão na vida dos homens. A compreensão da convivência de homens com hipertensão arterial deve orientar a construção e reorganização de políticas públicas voltadas para estes sujeitos.

\section{Colaborações:}

1 - concepção, projeto, análise e interpretação dos dados: Elilian Oliveira Pereira e Fernanda Carneiro Mussi;

2 - redação do artigo e revisão crítica relevante do conteúdo intelectual: Elilian Oliveira Pereira e Fernanda Carneiro Mussi;

3 - aprovação final da versão a ser publicada: Elilian Oliveira Pereira e Fernanda Carneiro Mussi.

\section{Referências}

1. World Health Organization. Global status report on noncommunicable diseases 2014 [Internet]. Genève; 2014 [cited 2015 Jan 1]. Available from: https://apps.who.int/iris/bitstream/e/10665/14811 4/9789241564854_g.f;jsessionid=30EAE93794DEB 3A7B2199646CF28902E?sequence $=1$

2. World Health Organization. Global Atlas on Cardiovascular Disease Prevention and Control [Internet]. Genève; 2011 [cited 2016 Mar 8]. Availablefrom:https://www.who.int/cardiovascular_ diseases/publications/atlas_cvd/en 
3. Sociedade Brasileira de Cardiologia. 7 Diretriz Brasileira de Hipertensão Arterial. Arq Brasil Cardiol [Internet]. 2016 [cited 2016 Dec 3];107(Supl3):1-83. Available from: http://publicacoes.cardiol.br/2014/ diretrizes/2016/05_HIPERTENSAO_ARTERIAL.pdf

4. Silva MA, Teixeira ER, Pereira ER, Silva RMCR, Rocha RCNP, Rondon SOB. Saúde como direito e cuidado de si: concepções de profissionais de enfermagem. Rev bras enferm. 2019;72(1):167-74. DOI: https://doi.org/10.1590/0034-7167-2018-0066

5. Santos JP. Illness x disease: uma abordagem antropológica sobre o sofrimento mental. Psicol Saberes. 2012;1(1):37-47. DOI: https://doi. org/10.3333/ps.v1i1.44

6. Langdon EJ, Wiik FB. Antropologia, saúde e doença: uma introdução ao conceito de cultura aplicado às ciências da saúde. Rev Latino-Am Enfermagem [online]. 2010;18(3):459-66. DOI: https://doi.org/10. 1590/S0104-11692010000300023

7. Canesqui AM. Olhares socioantropológicos sobre os adoecidos crônicos. São Paulo: Hucitec; 2007.

8. Fava SMCL, Zago MMF, Nogueira MS, Dázio EMR. Experiência da doença e do tratamento para a pessoa com hipertensão arterial sistêmica: um estudo etnográfico. Rev Latino-Am Enfermagem. 2013 Sept-Oct;21(5):1022-9. DOI: https://doi. org/10.1590/S0104-11692013000500003

9. Costa-Júnior FM, Couto MT, Maia ACB. Gênero e cuidados em saúde: concepções de profissionais que atuam no contexto ambulatorial e hospitalar. Sex Salud Soc. 2016;23:99-117. DOI: https://doi. org/10.1590/1984-6487.sess.2016.23.04.a

10. Brasil. Ministério da Saúde. Departamento de Vigilância de Doenças e Agravos não Transmissíveis e Promoção da Saúde. Secretaria de Vigilância em Saúde. Saúde Brasil 2014 uma análise da situação de saúde e das causas externas. Brasília (DF); 2015.

11. Stevens A, Schmidt MI, Duncan BB. Gender inequalities in noncommunicable disease mortalityin Brazil. Ciênc Saúde Coletiva. 2012 Oct;17(10):2627-34. DOI: http://dx.doi.org/10. 1590/S1413-81232012001000012

12. Brasil. Ministério da Saúde. Secretaria de Atenção à Saúde, Departamento de Ações Programáticas e Estratégicas. Política Nacional de Atenção Integral à Saúde do Homem. Brasília (DF); 2009.

13. Strauss A, Corbin J. Pesquisa qualitativa: técnicas e procedimentos para o desenvolvimento da teoria fundamentada. Porto Alegre: Artmed; 2018.
14. Galvão RRS, Soares DA. Prevalência de hipertensão arterial e fatores associados em adultos: uma revisão na literatura brasileira. Rev APS. 2016 jan/mar;19(1):139-49.

15. Andrade SSA, Stopa SR, Brito AS, Chueri PS, Szwarcwald CL, Malta DC. Prevalência de hipertensão arterial autorreferida na população brasileira: análise da Pesquisa Nacional de Saúde, 2013. Epidemiol Serv Saúde [online]. 2015;24(2):297-304. DOI: http://dx.doi.org/10. 5123/S1679-49742015000200012

16. Machado MC, Pires CGS, Lobão WM. Concepções dos hipertensos sobre os fatores de risco para a doença. Ciênc Saúde Coletiva [online]. 2012;17(5):1357-63. DOI: http://dx.doi. org/10.1590/S1413-81232012000500030

17. NESP. Perfil do Município de Salvador/BA. Análise do acesso e da qualidade da Atenção Integral à Saúde da população LGBT no Sistema Único de Saúde [Internet]. Salvador; 2016 [cited 2016 Dec 14]. Available from: http://www.nesp.unb.br/ saudelgbt/images/arquivos/Perfil_Salvador.pdf

18. 1Coutinho FHP, Sousa IMC. Percepção dos indivíduos com hipertensão arterial sobre sua doença e adesão ao tratamento medicamentoso na estratégia de saúde da família. Rev baiana saúde pública. 2011 abr-jun;35(2):397-411.

19. Silva SRA, Amorim RC, Almeida MA. Percepção de feirantes hipertensos sobre o adoecer crônico. Rev Enferm UERJ. 2015;23(6):761-6. DOI: https://doi. org/10.12957/reuerj.2015.8494

20. Altenhofen V, Castro EK. A percepção da doença cardíaca e da comunicação do diagnóstico. Psic Saúde Doenças. 2018 dez;19(3):515-25. DOI: http://dx.doi.org/10.15309/18psd19030104

21. Silva AC, Rudge AM. Construindo a noção de sintoma: articulações entre psicanálise e pragmática. Psicol USP. 2017;28(2):224-9. DOI: https://doi.org/10.1590/0103-656420160051

22. Suzano DS, Almeida MCS, Massa LDB, Wengert M. A importância da qualidade de vida em pacientes hipertensos. Saúde Redes [Internet]. 2016 [cited 2018 Mar 16];2(1):53-63. Available from: http://revista.redeunida.org.br/ojs/ index.php/rede-unida/article/view/660

23. Silva FM, Budó MLD, Silveira CL, Badke MR, Beuter M. Hypertension as a condition of nondisease - the meaning of chronicity in the subjects perspective. Texto contexto Enferm. 
2013 jan-mar;22(1):123-31. DOI: https://doi.org/10. 1590/S0104-07072013000100015

24. Ayres JRCM. O cuidado, os modos de ser (do humano) e as práticas de saúde. Saúde soc. 2004 set-dez;13(3):16-29.
Recebido: 2 de abril de 2020

Aprovado: 12 de maio de 2020

Publicado: 1 de julho de 2020

A Revista Baiana de Enfermagem utiliza a Licença Creative Commons - Atribuição-NãoComercial 4.0 Internacional. https://creativecommons.org/licenses/by-nc/4.0/ Este artigo é de acesso aberto distribuído sob os termos da Licença Creative Commons (CC BY-NC). Esta licença permite que outros remixem, adaptem e criem a partir do seu trabalho para fins não comerciais. Embora os novos trabalhos tenham de lhe atribuir o devido crédito e não possam ser usados para fins comerciais, os usuários não têm de licenciar esses trabalhos derivados sob os mesmos termos. 